\title{
Assessment of Senior Secondary School Teachers' Training and Usage of Information Communication Technology (Ict) In Science Teaching
}

\author{
Agommuoh, Patience $\mathbf{C}^{\mathbf{1}}$, Iroha Chineye $\mathbf{N}^{2}$, Sunday Ruth $\mathbf{N}^{3}$. \\ Benjane International Schools Umuahia; Department of Science Education, Michael Okpara University of \\ Agriculture, Umudike
}

\begin{abstract}
Information and Communication Technologies (ICTs) have been made an issue that cannot be ignored in education due to the growth of technology in both the public and private sectors of Nigeria's economy. This study employed the descriptive survey design to assess senior secondary school teachers training and usage of ICTs in the teaching of science. By the use of simple random technique,50(18males, 32females) out of a population of 104 senior secondary school science teachers in Umuahia North Local Government Area (LGA) of Umuahia Education Zone of Abia State. The instrument used for data collection was the researcher's developed questionnaire of the four point Likert type to elicit information on the training of teachers and usage of ICTs in the teaching of science in the Senior Secondary Schools. Four research questions and two hypotheses testing at 0.05 level of significance guided the study. The instrument was validated and its reliability obtained as 0.89 using Cronbach Alpha. Data collected was analyzed using mean to answer the research questions and test statistics to test the hypotheses. The study revealed that science teachers are trained in ICTs and that ICTs are also used in most aspect of science teaching in senior secondary school science. Recommendations were made based on the findings.
\end{abstract}

Keywords: Information and Communication Technology (ICT), Teaching, Learning and Science Education. 